\title{
Review
}

\section{Alveolar Bone Architecture: A Systematic Review and Meta-Analysis}

\author{
Alberto Monje, * Hsun-Liang Chan, * Pablo Galindo-Moreno, ${ }^{* \dagger}$ Basel Elnayef, ${ }^{\dagger}$ Fernando \\ Suarez-Lopez del Amo, * Feng Wang,§ and Hom-Lay Wang*
}

Background: There is a need for studying bone characteristics systematically for a better understanding of planning (i.e., timing of placement and loading) and outcomes of implant therapy. Therefore, the aim of the present review is to evaluate alveolar bone microarchitecture and its modifiers.

Methods: Two independent reviewers conducted electronic and manual literature searches in several databases, including MEDLINE, EMBASE, Cochrane Central Register of Controlled Trials, and Cochrane Oral Health Group Trials Register, for articles published up to February 2015 reporting alveolar bone microstructure. The random-effect model was applied to calculate the weighted mean (WM) of total bone volume (TBV), which has a range from 0 to 1 . TBV was stratified by anatomic locations, atrophic status, and types of specimens. Correlations between TBV and other bone-related parameters were also analyzed.

Results: A total of 800 articles were initially identified. After abstract/full-text review, 24 articles were included in the systematic review, of which 23 were also included in the quantitative analysis. The WM TBV was 0.365 (95\% confidence interval $=0.278$ to 0.452 ), higher in the maxillary/ mandibular anterior sites than the maxillary/mandibular posterior sites. However, great variations existed within each anatomic location. Additionally, WM TBV was lower in atrophic sites than non-atrophic sites. TBV was correlated negatively with trabecular spacing $\left(R^{2}=0.11\right)$.

Conclusions: The present systematic review suggests that the TBV might not be different between the defined anatomic locations. However, the atrophy status might influence TBV. J Periodontol 2015;86:1231-1248.

\section{KEY WORDS}

Alveolar bone grafting; bone and bones; dental implantation, endosseous; dental implants; evidence-based dentistry.

\footnotetext{
* Department of Periodontics and Oral Medicine, University of Michigan School of Dentistry, Ann Arbor, MI.

$\dagger$ Oral Surgery and Implant Dentistry Department, School of Dentistry, University of Granada, Granada, Spain.

† Department of Oral Surgery and Implantology, International University of Catalonia, Catalonia, Spain.

$\S$ Department of Oral Implantology, Ninth People's Hospital Affiliated with Shanghai Jiao Tong University, School of Medicine, Shanghai Key Laboratory of Stomatology, Shanghai, China.
}

A lveolar bone constitutes the most labile structure of the periodontium subject to continuous remodeling process because of its high sensitivity to external mechanical stimuli. ${ }^{1}$ As such, in the presence or absence of forces generated, the natural dentition potentially influences bone "quantity"2-4 and "quality." 5 Accordingly, after tooth extraction, a series of events trigger cellular and morphologic changes in alveolar bone architectural characteristics and dimensions. Amler et al. ${ }^{6}$ showed that 8 to 12 weeks after extraction, there is a mix of mature bone and osteogenic tissue that reaches its complete fill after 100 days in undisturbed sockets. Although mineralized tissue eventually repopulates the extraction socket, the healed socket changes in bone trabecular composition and orientation. It has been demonstrated that the alveolar socket is formed mostly by woven and "necrotic" bone, with numerous empty bone lacunae. ${ }^{7}$ Furthermore, $35 \%$ of the spontaneously healed sockets analyzed were considered "non-vital" empty lacunae that displayed as reduced osteoblastic activity, increased osteoclastic activity, and the presence of polymorphonuclear neutrophils. ${ }^{8}$ Bone grafting materials used for socket augmentation have influenced bone quality as well. ${ }^{9}$ Changes in bone quality and quantity have a significant influence on performance of implant therapy. ${ }^{10}$ 
As a matter of fact, bone characteristics may vary among different anatomic locations. ${ }^{5}$ It has been shown that a link exists between bone resorption rate and initial bone density before tooth extraction. ${ }^{5}$ It was evidenced that atrophy-related remodeling processes commence earlier and progress farther in posterior regions than in anterior and premolar sites. ${ }^{5}$ Furthermore, it has been shown after remodeling that trabecular organization was more haphazard in the posterior maxillary area compared to other sites. ${ }^{11}$ Hence, it seems logical that bone resorption may not occur equally in all regions; location may potentially influence bone characteristics. Misch ${ }^{12}$ proposed a bone density classification related to implant therapy based on the composition and measurable density reading from computed tomography (CT). According to this classification, D3-D4 bone, characterized by a porous thin layer of cortical bone and fine trabecular bone, is found primarily in the posterior maxilla, whereas D1-D2 bone represents a denser bone located commonly in the anterior and posterior mandibular ridges. ${ }^{12}$ Trisi and Rao ${ }^{13}$ validated the Misch classification with histomorphometric data. Interestingly, they failed to distinguish between D2 and D3 bone densities $(66.78 \pm 15 \%$ and $59.61 \pm 19 \%$, respectively, without statistical significance). Moreover, these types can be found randomly in the maxilla and mandible. Indeed, it seems that there is agreement regarding the influence of ridge (maxilla versus mandible) on bone density and composition, ${ }^{14-17}$ but little is known about the influence of location and anatomic characteristics on the resorptive process of alveolar bone after extraction.

Since commencement of implant therapy, bone quality has gained attention because it was thought to be related directly to implant success. ${ }^{13}$ Early studies demonstrated statistically significantly lower survival rates for implants placed in the posterior maxilla compared to other regions. ${ }^{18,19}$ However, this does not represent the current reality because of improvements in implant designs and the enriched knowledge in implant biomechanics. ${ }^{20}$ Nevertheless, bone characteristics strongly influence the degree of primary stability that can be achieved. How much primary stability is necessary? Evidence suggests that excessive primary stability may be harmful to bone homeostasis. ${ }^{21}$ Higher torque, an indicator of high primary stability, has been shown to be associated with a zone of dead and dying osteocytes, along with microfractures that lead to greater periimplant bone resorption. ${ }^{21}$ In other words, is bone with low density truly poorer in terms of quality?22 Certainly, primary stability is provided by a proportion of the mineralized bone tissue component, which has been traditionally confused with the cortical bone thickness; notwithstanding, in a lower proportion of bone marrow, a lower proportion of mesenchymal progenitor cells, mononuclear precursors, and endothelial cells and vessels needed for adequate biologic stability are expected. ${ }^{23}$ It is also important to keep in mind that reparation after trauma, such as implant insertion, is guided by these biologic components that are mainly located in the non-mineralized bone component. Therefore, poor mechanical quality may represent a high potential for faster biologic integration. ${ }^{22}$

Bone characteristics and their determinant factors should be studied comprehensively to better understand their effect on implant therapy planning (i.e., placing and loading) and its outcomes. As such, the current systematic review aims to evaluate bone microarchitecture at the different regions of the human oral cavity and the anatomic/intrinsic factors that could influence them.

\section{MATERIALS AND METHODS}

\section{Information Sources}

Electronic and manual literature searches were conducted by two independent reviewers (AM and $\mathrm{BE}$ ) in several databases, such as MEDLINE, EMBASE, Cochrane Central Register of Controlled Trials, and Cochrane Oral Health Group Trials Register, for articles published up to February 2015 without language or year restriction.

\section{Focused Modified PICO Question and Outcome Measures}

P: problem/patient. Complete or partially edentulous healthy individuals (i.e., no presence of systemic infectious diseases at the moment of implant insertion and no presence of serious diseases or conditions known to alter bone metabolism, such as osteoporosis, renal disease, oncologic disease, or disturbance of the calcium metabolism) with nonatrophic/atrophic maxillary/mandibular pristine ridges were included.

I: intervention. No real interventions were evaluated for ethical issues. However, the types of analysis to study bone characteristics were considered as the interventions: direct bone microstructure assessment (i.e., histomorphometric analysis, micro-CT, dualphoton absorptiometry, or back-scattered electron microscopy) in living individuals or human cadavers.

C: comparison. Different location and anatomic considerations in the edentulous sites were compared: 1) anterior versus posterior; 2) maxillary versus mandibular; and 3) atrophic versus nonatrophic.

O: outcome. The primary outcome was total bone volume (TBV), which is the total amount of bone present in relation to the analyzed bone volume. It is a parameter used widely in pathologies that alter 
bone turnover because it perfectly reflects bone gain/ loss. It indicates the fraction of a given volume of interest occupied by mineralized tissue. Therefore, implant anchoring at implant placement will rely primarily on this parameter.

Secondary outcomes included both direct metric parameters and non-direct parameters. The direct metric parameters were as follows. 1) Trabecular thickness (Tb.Th) is used to analyze the bone fill and to determine the mean thickness of the osseous structures. 2) Trabecular spacing (Tb.Sp) is used to detect the marrow spaces and thus should be correlated to TBV: the more TBV, the less Tb.Sp. ${ }^{24}$ Therefore, this parameter inversely determines bone density. 3) Trabecular number (Tb.N) implies the number of times the trabeculae are crossed by means of length in a randomly selected way across the bone volume analyzed. 4) Trabecular pattern (Tb.Pf) quantitatively describes trabecular connectivity. ${ }^{25}$ It is an inverse connectivity index. Therefore, concavity of the trabecular surfaces implies connectivity, whereas convexity means isolated and misconnected structures.

Non-direct parameters were as follows. 1) The structural model index (SMI) determines the relative presence of either plate- or rod-like trabeculae. It is defined in a range of 0 to 3 , in which 0 corresponds to an ideal plate and 3 to an ideal cylinder. ${ }^{26}$ Normally, plate-like trabeculae are associated with a higher osseous stiffness. 2) Degree of anisotropy (DA) measures the presence or absence of structures lined in a specific direction. Thus, biopsies analyzed with a high DA indicate that the trabeculae are oriented in the same direction. Mechanical anisotropy means that the mechanical properties are different for measuring different directions in the same sample. ${ }^{27}$ Therefore, DA is probably the most important determinant of biomechanical strength. ${ }^{28} 3$ ) Bone mineral density (BMD) compares the attenuation coefficients of two hydroxyapatite patterns of known density $\left(250\right.$ and $750 \mathrm{mg} / \mathrm{cm}^{3}$ ). This is an area density and not a true volume density because it has a dependency on bone size. ${ }^{29} 4$ ) Microscopic bone composition includes lamellar bone, containing parallel, spirally arranged collagen fibers, and woven bone, which has a haphazard collagen organization.

\section{Screening Process}

For the PubMed library, combinations of controlled terms (MeSH and EMTREE) and key words were used when possible. Other terms not indexed as $\mathrm{MeSH}$ and filters were applied also. As such, the key terms used included the following: $((()(($ maxilla [MeSH Terms]) OR maxillae [MeSH Terms]) OR mandible [MeSH Terms]) OR alveolar bone [Title/ Abstract]) OR density [Title/Abstract]) OR quality
[Title/Abstract]) OR architecture [MeSH Terms]) OR trabecular [Title/Abstract]) AND histology [MeSH Terms]) OR micro computed tomography, $\mathrm{x}$ ray [MeSH Terms]). This preliminary screening was limited to 'humans' and 'clinical trials.' A second broader screening was conducted due to the small number of articles found indexed with the preliminary screening strategy: ((()(((alveolar [Title/Abstract]) AND maxilla [Title/Abstract]) OR mandible [Title/ Abstract]) AND pristine [Title/Abstract]) OR native [Title/Abstract]) AND bone [Title/Abstract]) OR process [Title/Abstract]) AND histomorphometric [Title/Abstract]) OR histomorphometry [Title/Abstract]) OR micro computed tomography [Title/Abstract]) OR microCT [Title/Abstract]) OR histology [Title/ Abstract]). Again, "humans" and "clinical trials" were applied as restricted studies.

For the EMBASE and Cochrane libraries, the key terms used were (Title, Abstract, Keywords): bone architecture AND maxilla OR bone architecture AND mandible OR bone density AND maxilla OR bone density AND mandible OR bone quality AND maxilla OR bone quality AND mandible OR total bone volume AND maxilla OR total bone volume AND mandible. The screening in such databases were limited to "clinical trials" AND "humans." An electronic screening of the "gray literature" at the New York Academy of Medicine Gray Literature Report was conducted as recommended by high standards for systematic reviews (Assessment of Multiple Systematic Reviews guidelines). ${ }^{30}$

Additionally, a manual search of periodonticsrelated/implant-related journals, including Journal of Periodontology, Clinical Implant Dentistry and Related Research, Clinical Oral Implants Research, Implant Dentistry, Journal of Clinical Periodontology, Journal of Dental Research, Journal of Oral and Maxillofacial Implants, and The International Journal of Periodontics \& Restorative Dentistry, from January 2000 to February 2015, was also performed to ensure a thorough screening process. Furthermore, references of included articles were screened to check all available articles.

\section{Eligibility Criteria}

Articles are included in this systematic review if they met the following criteria: randomized controlled prospective or retrospective, cohort or case series studies involving human participants aimed at showing bone microstructure by means of TBV in the different locations of the oral cavity. Articles in which the location could not be extracted clearly were included in the qualitative but not in the quantitative analysis (meta-analysis). Accordingly, several factors were retrieved from the studies: 1) study design; 2) number of examinations (biopsies); 3) specimen; 4) 


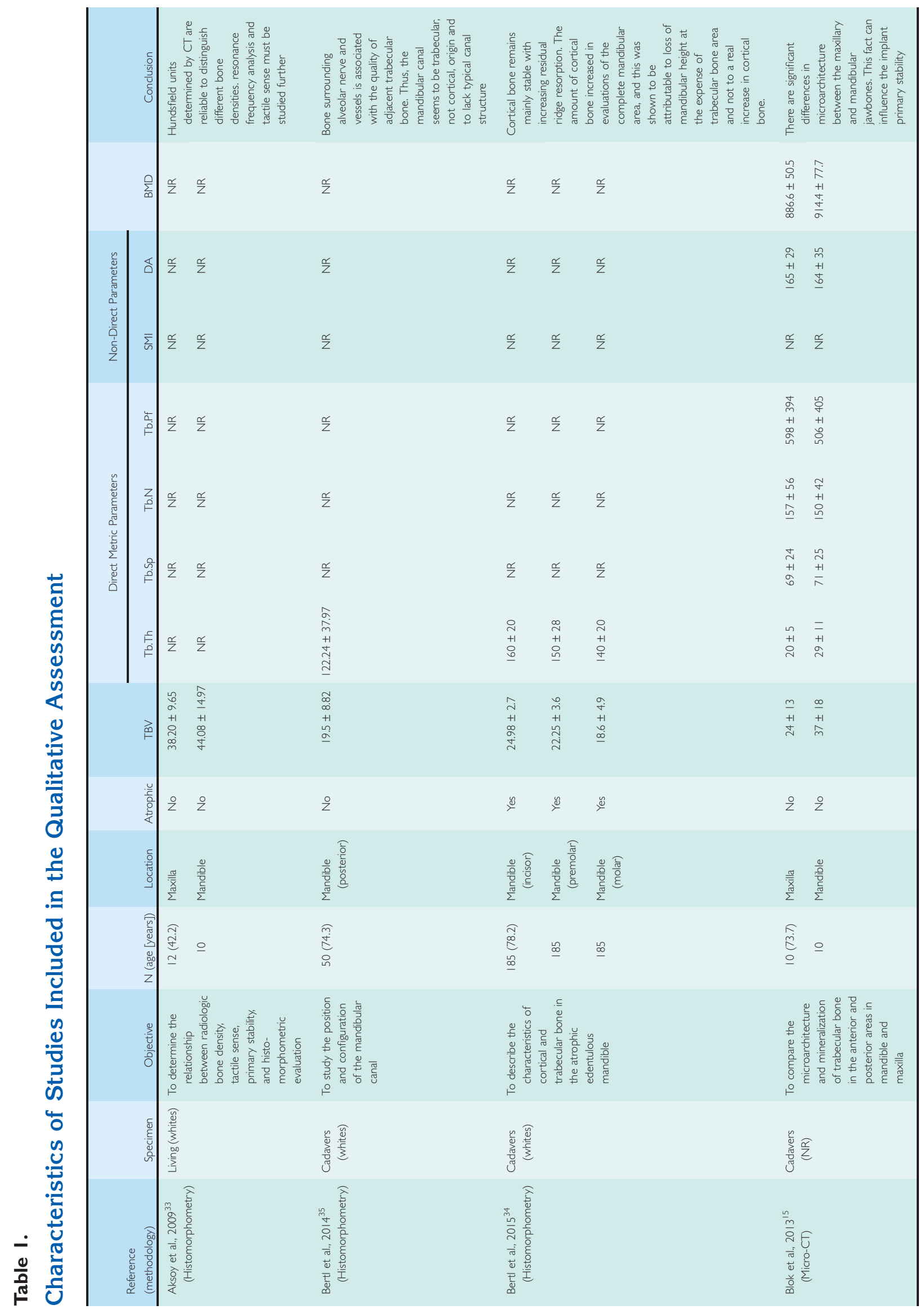




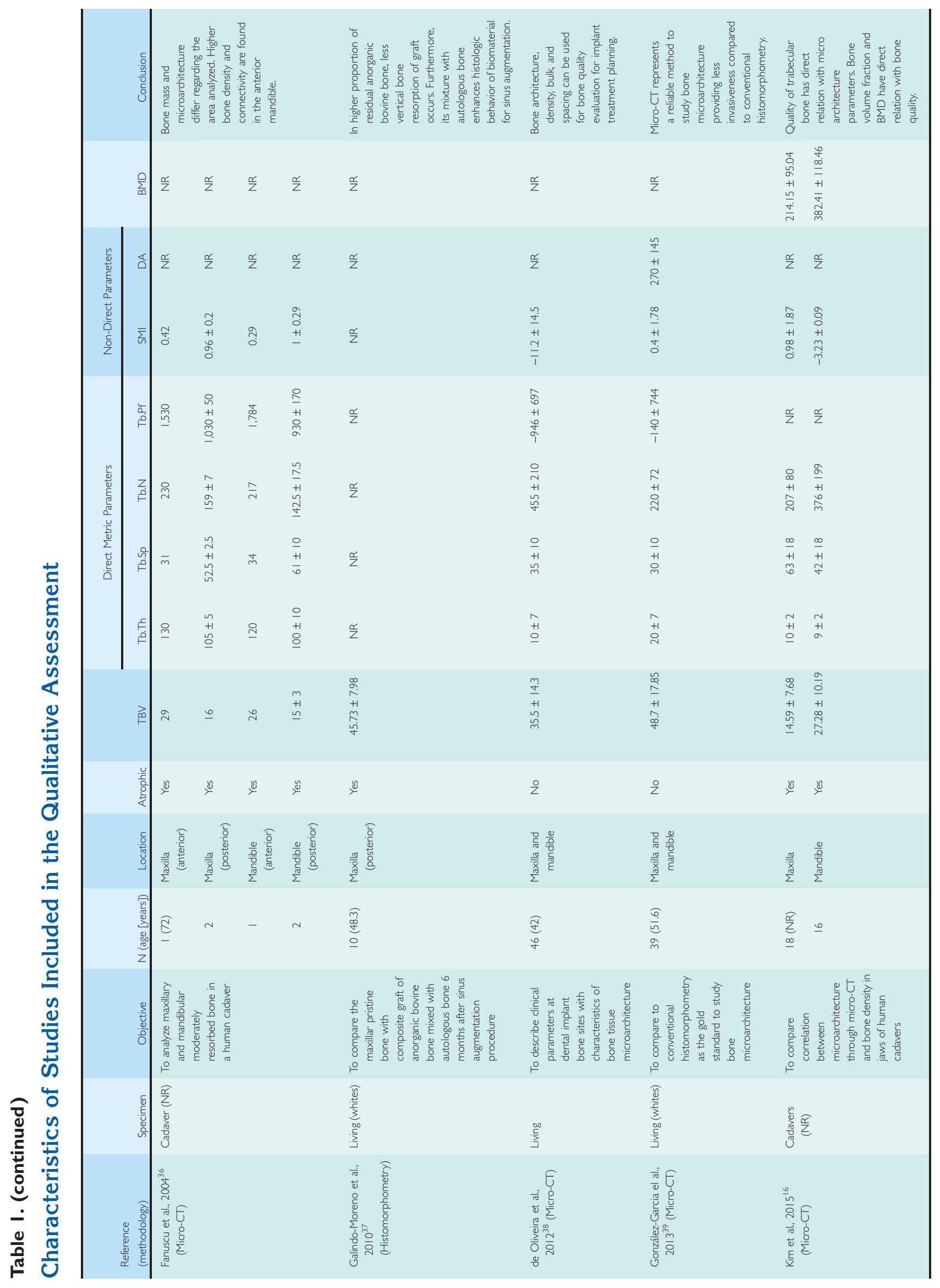




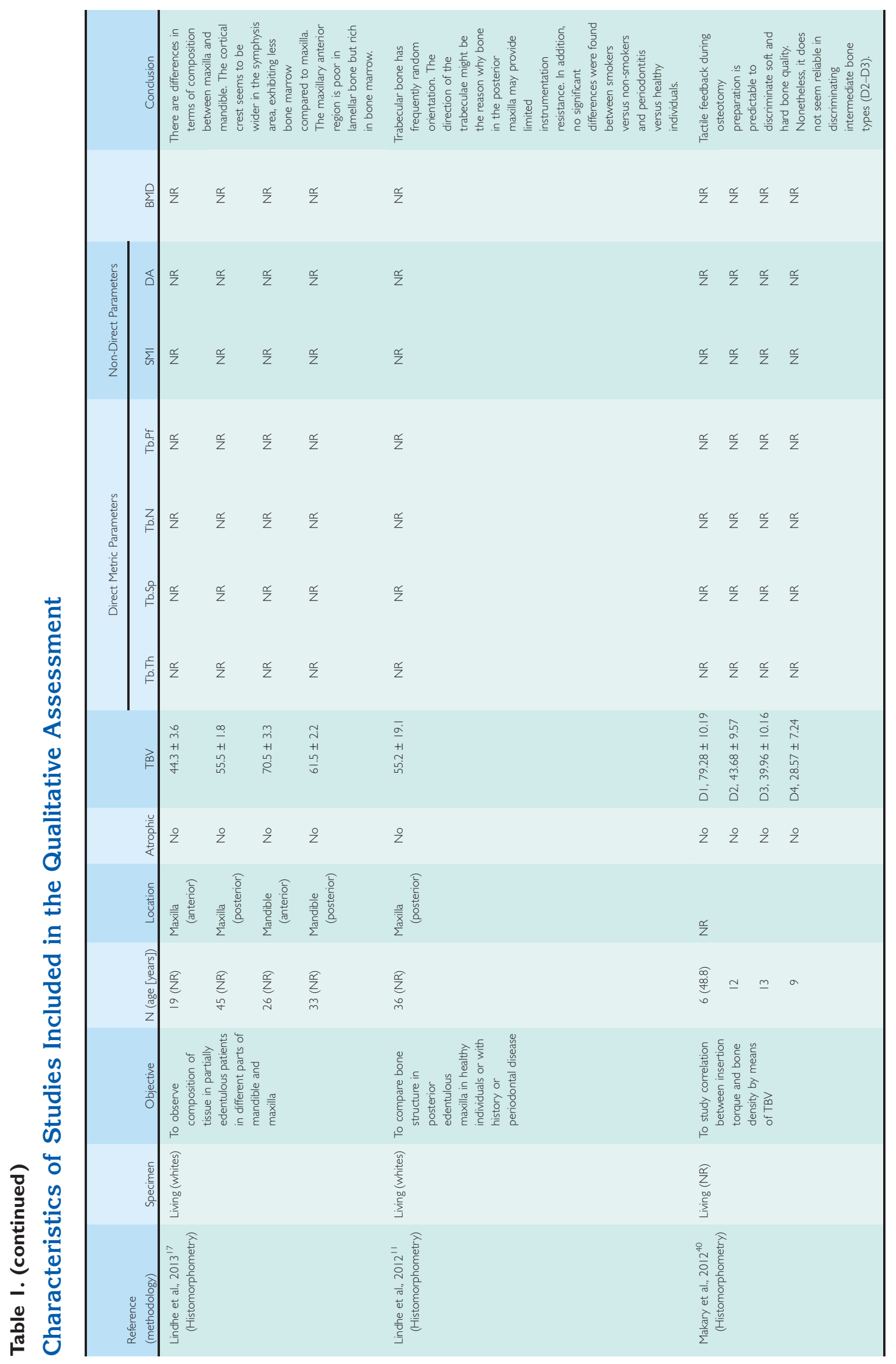




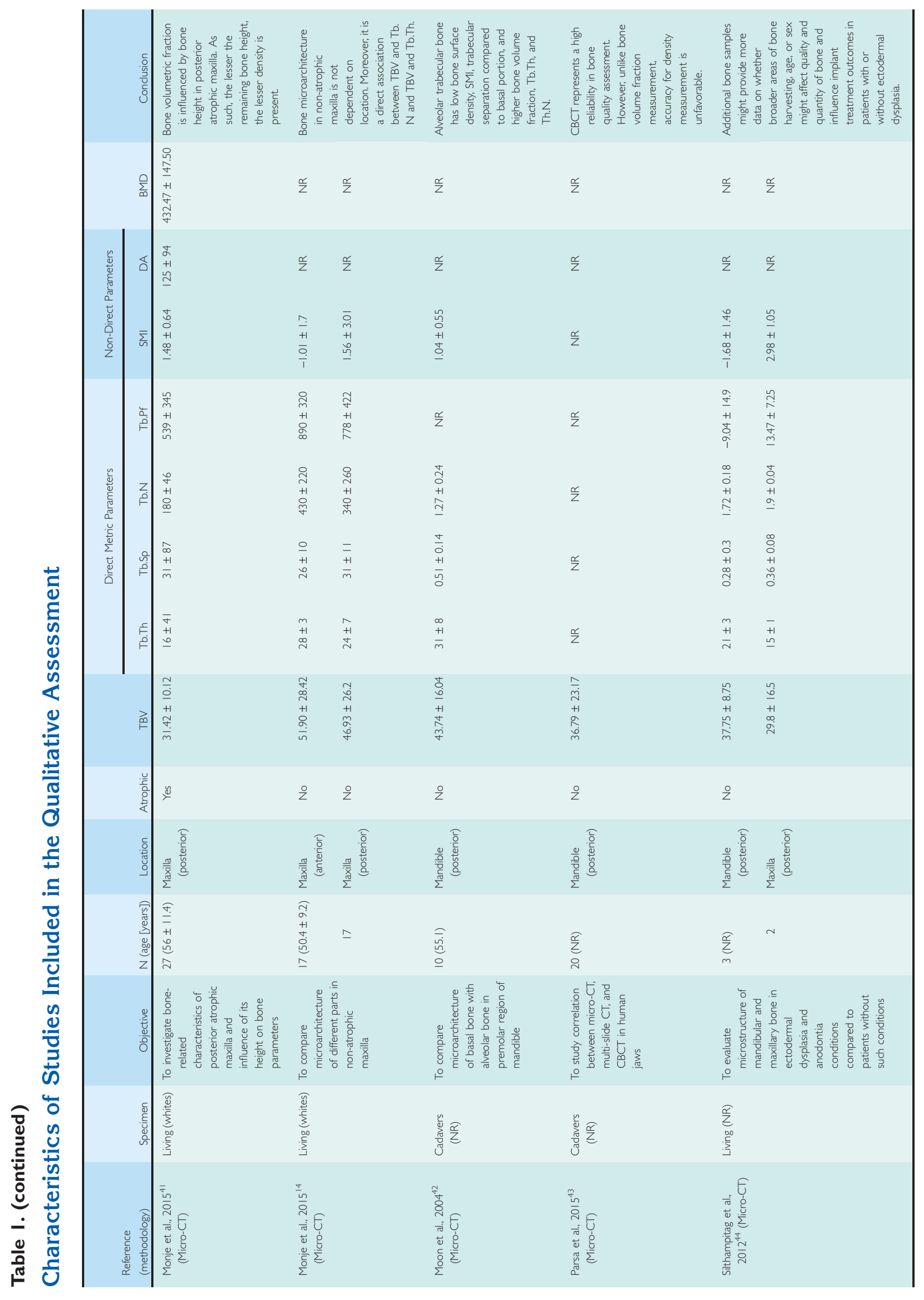




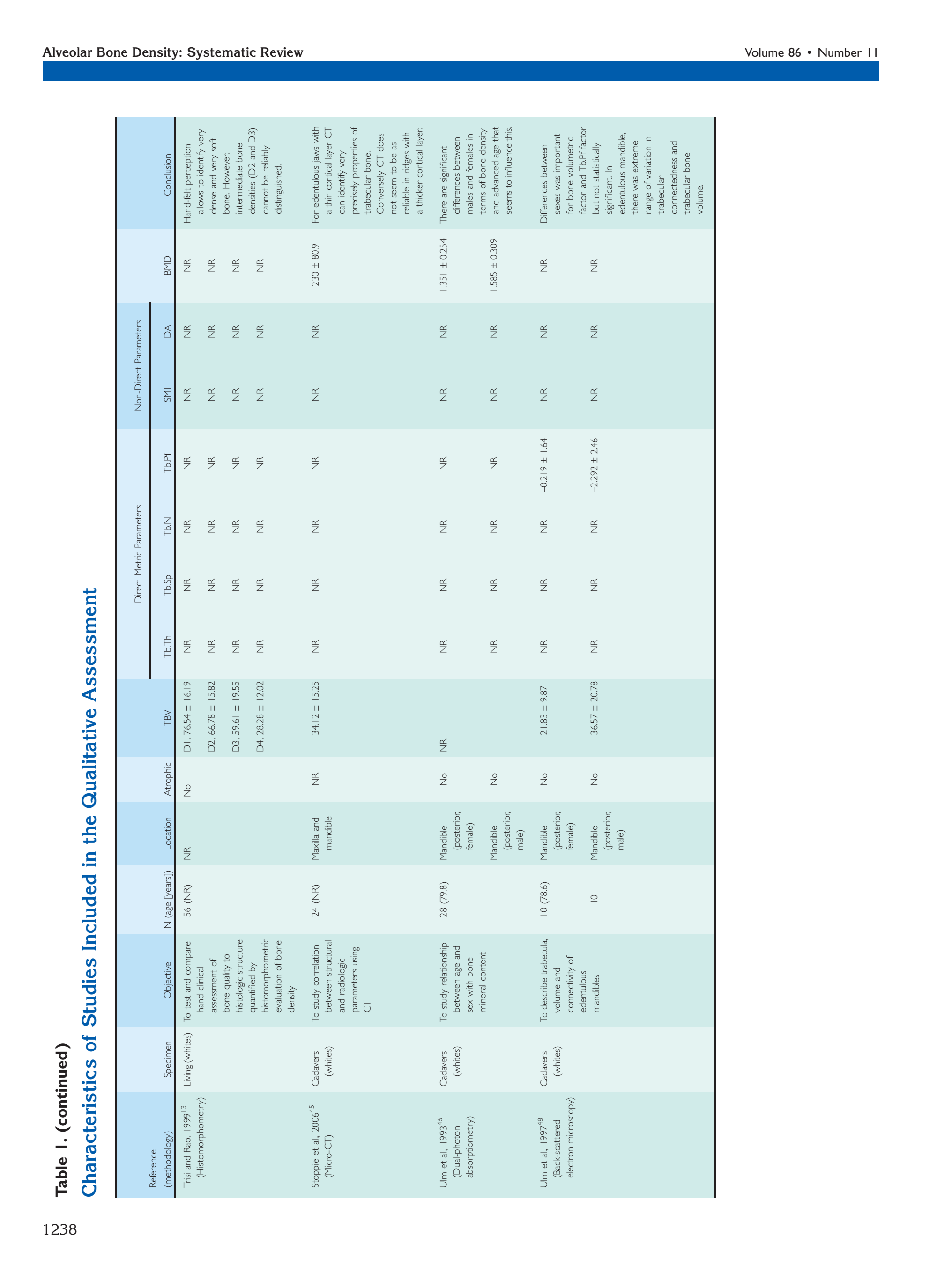




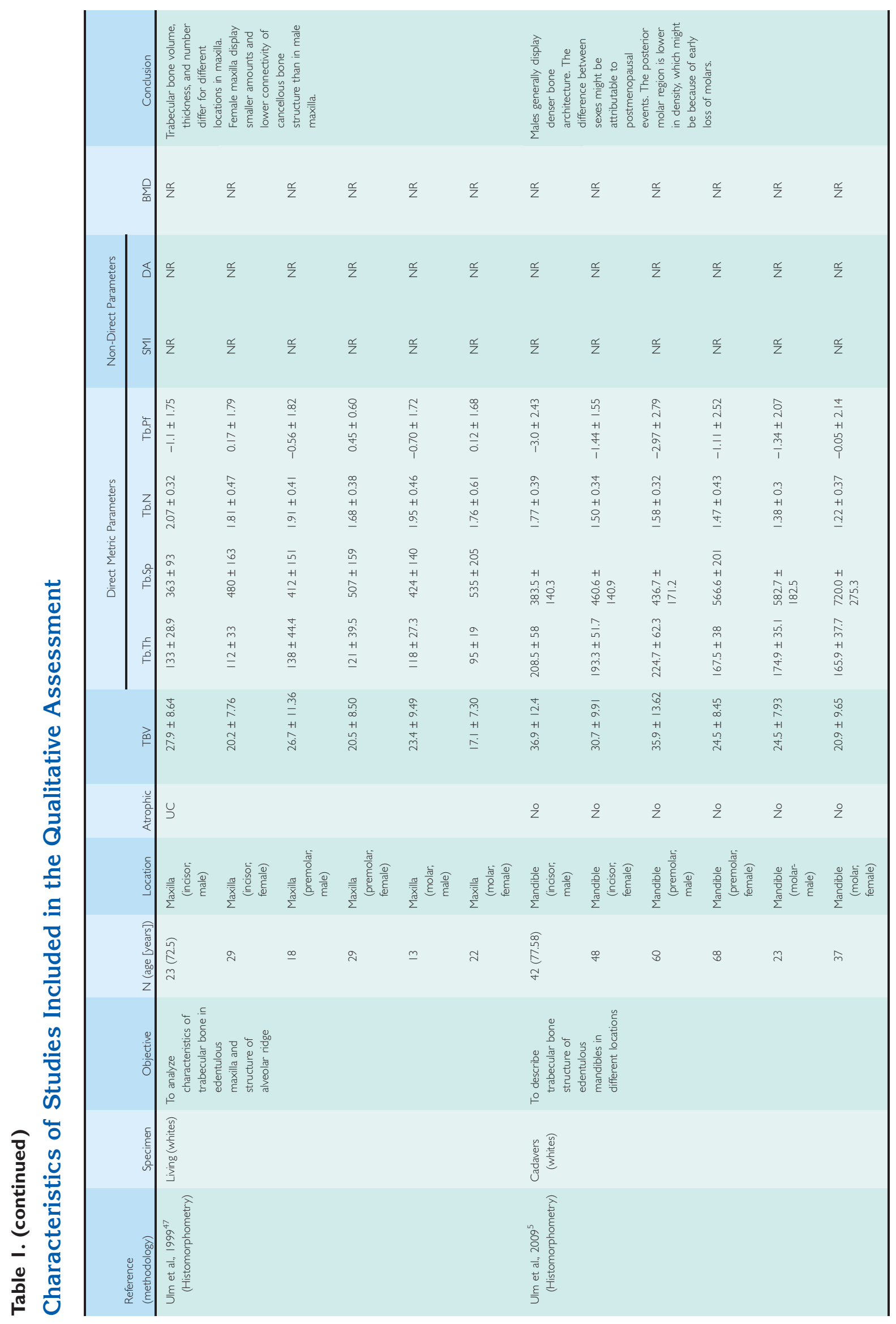




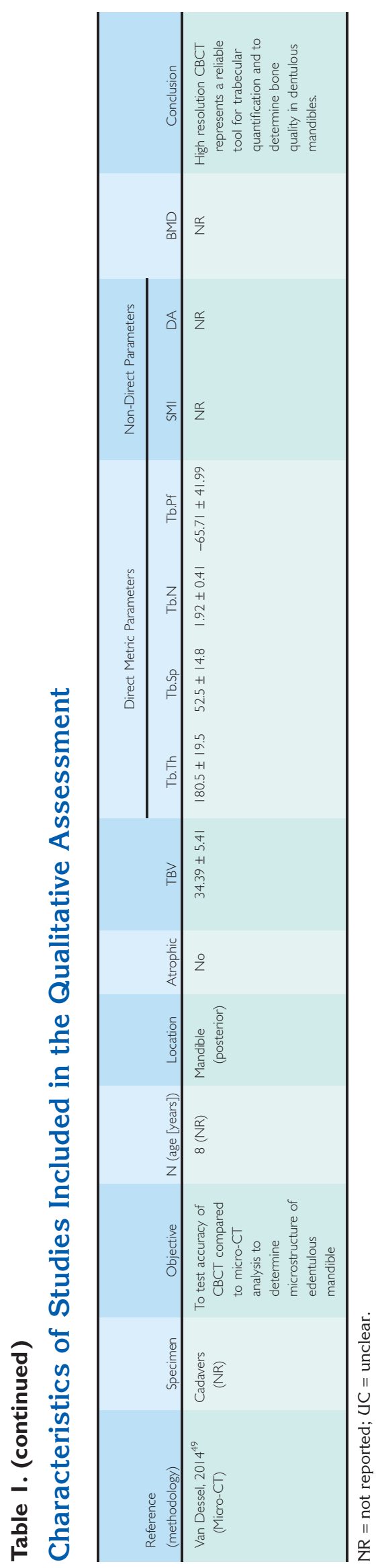

age; 5) sex; 6) location; 7) vertical dimension (in millimeters); 8) horizontal dimension (in millimeters); 9) atrophy condition (according to each author's definition of atrophy); 10) TBV; 11) direct and non-direct parameters; 12) DA; 13) SMI; 14) thickness of the cortical layer (in millimeters); and 15) woven and lamellar bone (percentage). Moreover, to have better qualitative assessment of the included articles, the sections "objective" and "conclusion" were summed up for each study (Table 1). Conversely, the following were excluded for qualitative and quantitative assessments: 1) case reports or case series with less than five samples studied; 2) systematic reviews; 3) preclinical animal studies; and 4) human trials studying bone quality by means of indirect methods (i.e., Hounsfield unit [CT], "grayscale" [cone-beam CT (CBCT)], implant stability quotient [resonance frequency analysis], implant stability value [electronic mobility testing device], implant torque, or surgical feeling). Human trials with missing information were also excluded (see supplementary Table 1 in online Journal of Periodontology).

Risk of Bias and Qualitative Assessment

Two reviewers (AM and BE) designed and assessed the proposal for the present project to ensure the PRISMA (Preferred Reporting Items for Systematic Reviews and Meta-Analyses) guidelines were followed to avoid risk of bias and provide high-quality evidence. PRISMA consists of a 27 -item checklist and a four-phase flow diagram. ${ }^{31}$

Two independent reviewers (AM and BE) evaluated all the included articles. The Newcastle-Ottawa scale (NOS) was proposed to assess the quality of such studies for a proper understanding of nonrandomized studies. ${ }^{32}$ Nonetheless, for these types of studies (morphometric examination of pristine bone in which no real intervention is evaluated), the nature of the research does not act as a determinant for the results. Therefore, a modified NOS scale was applied. Although it needs validation by additional studies, this novel qualitative assessment checklist, namely the Michigan scale, is proposed to be applied for future investigations on the study of pristine/grafted alveolar bone (see supplementary Fig. 1 in online Journal of Periodontology). It consists of a total of 10 items for critical appraisal of studies involving grafted bone and eight items for investigations on pristine bone divided into three sections: selection, comparison, and outcome (as proposed by the original NOS). Each item can be reached with a maximum of one star. Therefore, like NOS, quality is based on the number of stars reached.

\section{Statistical Analyses}

The primary outcome was the TBV of the alveolar bone. The value of TBV ranges from 0 to 1 . The 


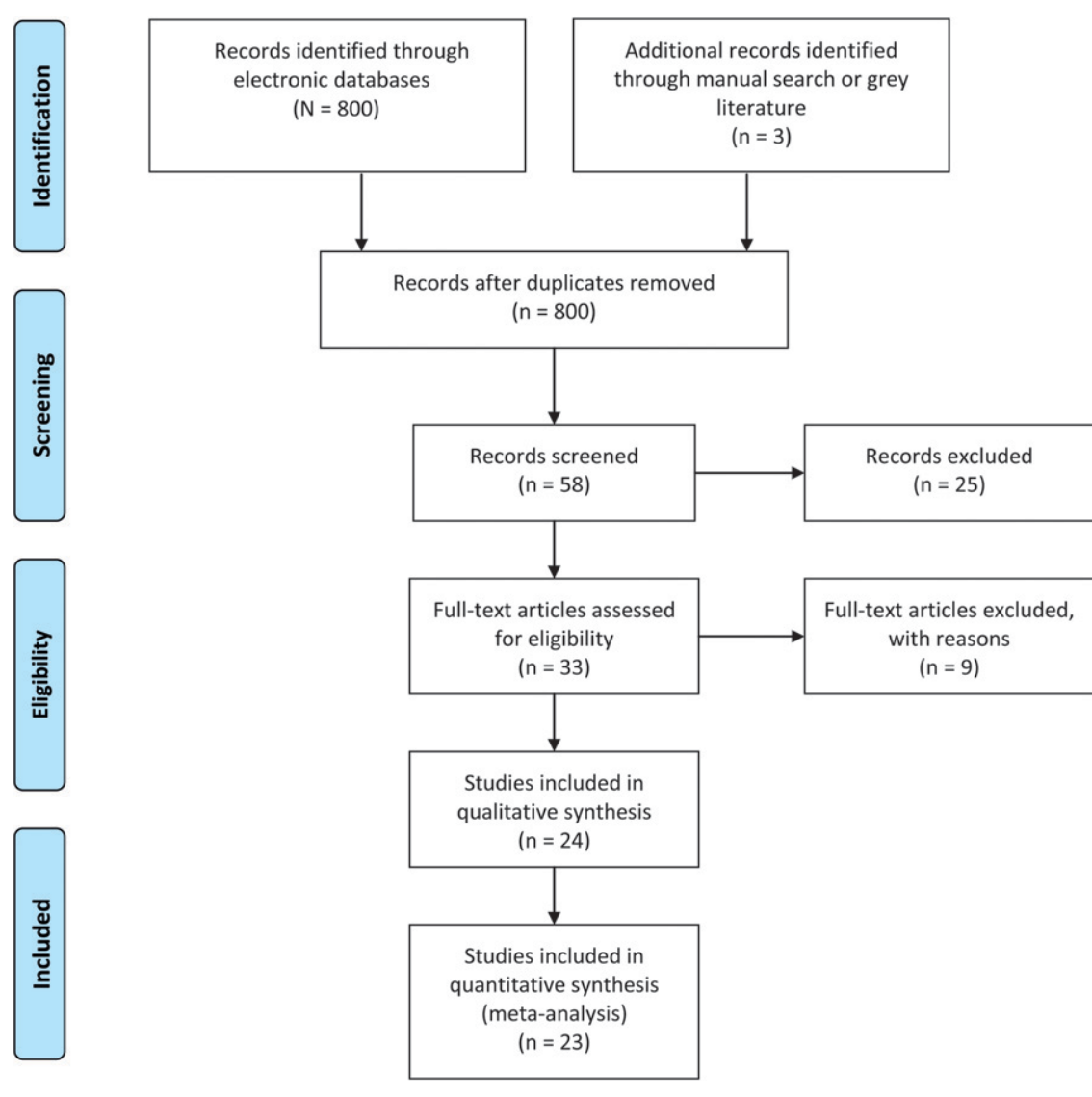

Figure I. PRISMA flowchart of the screening process in the different databases. ${ }^{31}$

terventions, $P$ of $0 \%$ to $40 \%$ might suggest unimportance of heterogeneity, whereas $30 \%$ to $60 \%$ suggests moderate, $50 \%$ to $90 \%$ substantial, and $75 \%$ to $100 \%$ considerable heterogeneity. Publication biases were presented with a funnel plot for each meta-analysis.

\section{RESULTS}

\section{Study Selection}

An initial screening yielded a total of 800 articles (313 [PubMed Library], 313 [EMBASE], and 174 [Cochrane Library]), of which 33 potentially relevant articles were selected after an evaluation of their titles and abstracts. Full text of these articles was obtained and evaluated thoroughly. Of these, only 24 articles $5,11,13-17,33-49$ fulfilled the inclusion criteria and subsequently were included in the qualitative synthesis (Fig. 1). Reasons for exclusion are displayed in supplementary Table 1 in online Journal of Periodontology. Of the 24 articles included in the systematic review, 235,11,13-17,33-45,47-49 were also included in the quantitative synthesis and meta-analyzed to extract the influence of the variables on

pooled weighted mean (WM) and the $95 \%$ confidence interval (CI) of TBV were estimated using a computer program. "To further evaluate potential differences in TBV among various anatomic sites, WM of TBV and the $95 \% \mathrm{CI}$ at four regions (maxillary anterior, maxillary posterior, mandibular anterior, and mandibular posterior) were calculated separately. Incisors and canines are considered anterior sites, and premolars and molars are considered posterior sites. The random-effect model was applied when performing meta-analyses to account for methodologic differences among studies. Forest plots were produced to graphically represent WM and 95\% CI for the outcome using "site" as the analysis unit. To evaluate the possibility of atrophic status of alveolar bone on TBV, WM of TBV in atrophic and non-atrophic sites was calculated separately. The correlations of TBV with other bone parameters were plotted with commercially available software ${ }^{\mathbb{I l}}$ and presented as $R^{2}$.

\section{Heterogeneity and Publication Bias}

Heterogeneities were examined by calculating $Q$ with significance level at $0.1, R$, and $\tau^{2}$ using the same software. As a general guideline defined by the Cochrane Handbook for Systematic Reviews of In- bone density parameters. Details of all included studies are summarized in Table 1.

\section{Qualitative Analyses}

All the articles included in the present systematic review are prospective or retrospective non-randomized trials aimed at studying alveolar bone density. The Michigan scale was applied for studies involving pristine bone characteristics (see supplementary Fig. 1 in online Journal of Periodontology). According to this, a score of $6.95 \pm 1.04$ was obtained, showing the high quality of the studies included for the qualitative synthesis. A high inter-rater agreement was obtained $(k=0.89)$. Complete consensus was reached by discussion.

\section{Influence of Location on Primary Outcome}

A total of 23 publications with 1,095 study sites were available for data extraction. The TBV ranges from $0.15^{36}$ to $0.59,{ }^{13}$ with the WM of TBV being 0.365 (95\% CI $=0.278$ to 0.452 ) (Fig. 2A). Taking anatomic location into consideration, the WM of TBV in the maxillary anterior, maxillary posterior,

\| Comprehensive Meta-Analysis v.2, Biostat, Englewood, NJ.

II Excel, Microsoft, Seattle, WA. 


\begin{tabular}{|c|c|c|c|c|c|}
\hline \multirow[t]{2}{*}{ A Study } & \multicolumn{5}{|c|}{ Statistics } \\
\hline & Mean & $\begin{array}{l}\text { Standard } \\
\text { error }\end{array}$ & $\begin{array}{c}\text { Lower } \\
\text { limit }\end{array}$ & $\begin{array}{c}\text { Upper } \\
\text { limit }\end{array}$ & Total \\
\hline Aksoy et al. $(2009)^{33}$ & 0.410 & 0.026 & 0.360 & 0.460 & 22 \\
\hline Bertl et al. $(2014)^{35}$ & 0.200 & 0.013 & 0.175 & 0.225 & 50 \\
\hline Bertl et al. $(2015)^{34}$ & 0.220 & 0.003 & 0.214 & 0.226 & 185 \\
\hline Block et al. $(2013)^{15}$ & 0.310 & 0.036 & 0.240 & 0.380 & 20 \\
\hline Fanuscu et al. $(2004)^{36}$ & 0.150 & 0.021 & 0.108 & 0.192 & 2 \\
\hline Galindo-Moreno et al. $(2010)^{37}$ & 0.460 & 0.025 & 0.410 & 0.510 & 10 \\
\hline González-Garcia el al. (2013) & 0.490 & 0.029 & 0.434 & 0.546 & 39 \\
\hline Kim et al. $(2015)^{16}$ & 0.210 & 0.015 & 0.180 & 0.240 & 34 \\
\hline Lindhe et al. (2012) 11 & 0.550 & 0.032 & 0.488 & 0.612 & 36 \\
\hline Lindhe et al. $(2013)^{17}$ & 0.586 & 0.003 & 0.581 & 0.591 & 123 \\
\hline Makary et al. $(2012)^{40}$ & 0.440 & 0.014 & 0.412 & 0.468 & 40 \\
\hline Monje et al. (2015) ${ }^{41}$ & 0.310 & 0.019 & 0.272 & 0.348 & 27 \\
\hline Monje et al. $(2015)^{14}$ & 0.500 & 0.046 & 0.409 & 0.591 & 34 \\
\hline Moon et al. $(2004)^{42}$ & 0.440 & 0.051 & 0.341 & 0.539 & 10 \\
\hline de Oliveira et al. $(2012)^{38}$ & 0.360 & 0.021 & 0.320 & 0.400 & 46 \\
\hline Parsa et al. $(2015)^{43}$ & 0.370 & 0.051 & 0.269 & 0.471 & 20 \\
\hline Sitthampitag et al. $(2011)^{44}$ & 0.346 & 0.054 & 0.241 & 0.451 & 5 \\
\hline Stoppie et al. $(2006)^{45}$ & 0.340 & 0.031 & 0.280 & 0.400 & 24 \\
\hline Trisi \& Rao (1999) ${ }^{13}$ & 0.580 & 0.021 & 0.538 & 0.622 & 56 \\
\hline Ulm et al. $(1997)^{48}$ & 0.220 & 0.022 & 0.176 & 0.264 & 20 \\
\hline Ulm et al. $(1999)^{47}$ & 0.270 & 0.009 & 0.253 & 0.287 & 156 \\
\hline Ulm et al. $(2009)^{5}$ & 0.300 & 0.009 & 0.283 & 0.317 & 128 \\
\hline Van Dessel $(2013)^{49}$ & 0.340 & 0.018 & 0.305 & 0.375 & 8 \\
\hline & 0.365 & 0.044 & 0.278 & 0.452 & 1,095 \\
\hline
\end{tabular}

\section{B Study}

Statistics Mean and $95 \% \mathrm{Cl}$

$\begin{array}{lccccc} & \text { Mean } & \begin{array}{c}\text { Standard } \\ \text { error }\end{array} & \begin{array}{c}\text { Lower } \\ \text { limit }\end{array} & \begin{array}{c}\text { Upper } \\ \text { limit }\end{array} & \text { Total } \\ \text { Lindhe et al. (2013) } & 0.440 & 0.009 & 0.422 & 0.458 & 19 \\ \text { Monje et al. (2015) } & 0.520 & 0.068 & 0.387 & 0.653 & 17 \\ \text { Ulm et al. (1999) } & 0.370 & 0.044 & 0.284 & 0.456 & 23 \\ \text { Ulm et al. (1999) } & 0.280 & 0.017 & 0.247 & 0.313 & 29 \\ & 0.395 & 0.055 & 0.287 & 0.502 & 88\end{array}$

Mean and $95 \% \mathrm{Cl}$

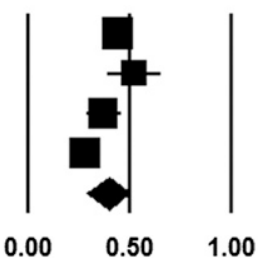

Figure 2.

A) WM of TBV obtained from all the studies included in the quantitative analysis. B) WM of TBV in the maxillary anterior region. C) WM of TBV in the maxillary posterior region. D) WM of TBV in the mandibular anterior region. E) WM of TBV in the mandibular posterior region.

mandibular anterior, and mandibular posterior regions are 0.395 ( $\mathrm{n}=88$ sites, $95 \% \mathrm{CI}=0.287$ to 0.502 ) (Fig. 2B), 0.357 ( $\mathrm{n}=219$ sites, $95 \% \mathrm{CI}=$ 0.233 to 0.481 ) (Fig. 2C), 0.375 ( $\mathrm{n}=301$ sites, $95 \%$ $\mathrm{CI}=0.102$ to 0.648$)$ (Fig. 2D), and $0.306(\mathrm{n}=694$ sites, $95 \% \mathrm{CI}=0.194$ to 0.419 ) (Fig. $2 \mathrm{E}$ ), respectively. Although there is a trend to show a higher TBV in the maxillary and mandibular anterior sites than in maxillary and mandibular posterior sites, there exist great variations within each anatomic location (Fig. 3).

\section{Influence of Patient-Related Factors on Primary Outcome}

The WM of TBV in atrophic sites is 0.268 ( $\mathrm{n}=$ $258,95 \% \mathrm{CI}=0.199$ to 0.337 ) compared to 0.406 ( $\mathrm{n}=802$ sites, $95 \% \mathrm{CI}=0.327$ to 0.486$)$ in nonatrophic sites (Fig. 4). No comparison of TBV between edentulous and dentate sites is available because no included study directly made such comparison; however, the results mentioned above suggested that the bone volume is statistically significantly higher in non-atrophic sites. The WM of TBV in the living individuals and cadaver specimens is $0.446(\mathrm{n}=589$ sites, $95 \% \mathrm{CI}=0.359$ to 0.534 ) and $0.285(\mathrm{n}=501$ sites, $95 \% \mathrm{Cl}=0.248$ to 0.323 ), respectively. This result suggested that TBV might be higher in living individuals than in cadaver specimens.

\section{Correlation of Secondary Outcomes With Primary Outcome}

The $R^{2}$ of the correlation between TBV and Tb.Sp was 0.11 (Fig. 5), suggesting a weak correlation between the bone-related parameters mentioned above. Correlations between the other bone-related parameters were either below 0.1 or not available as a result of too few sample sizes available. 


\begin{tabular}{|c|c|c|c|c|c|}
\hline \multirow[t]{2}{*}{ C Study } & \multirow[b]{2}{*}{ Mean } & \multicolumn{4}{|c|}{ Statistics } \\
\hline & & $\begin{array}{l}\text { Standard } \\
\text { error }\end{array}$ & $\begin{array}{l}\text { Lower } \\
\text { limit }\end{array}$ & $\begin{array}{c}\text { Upper } \\
\text { limit }\end{array}$ & Total \\
\hline Galindo-Moreno et al. $(2010)^{37}$ & 0.460 & 0.025 & 0.410 & 0.510 & 10 \\
\hline Lindhe et al. $(2012)^{11}$ & 0.550 & 0.032 & 0.488 & 0.612 & 36 \\
\hline Lindhe et al. $(2013)^{17}$ & 0.555 & 0.003 & 0.550 & 0.560 & 45 \\
\hline Monje et al. $(2015)^{41}$ & 0.310 & 0.019 & 0.272 & 0.348 & 27 \\
\hline Monje et al. $(2015)^{14}$ & 0.470 & 0.063 & 0.346 & 0.594 & 17 \\
\hline Ulm et al. (1999) ${ }^{47}$ & 0.210 & 0.019 & 0.173 & 0.247 & 18 \\
\hline Ulm et al. $(1999)^{47}$ & 0.210 & 0.025 & 0.161 & 0.259 & 13 \\
\hline Ulm et al. $(1999)^{47}$ & 0.270 & 0.020 & 0.230 & 0.310 & 29 \\
\hline Ulm et al. $(1999)^{47}$ & 0.230 & 0.019 & 0.192 & 0.268 & 22 \\
\hline \multirow[t]{2}{*}{ Silthampitag et al. $(2011)^{44}$} & 0.300 & 0.120 & 0.064 & 0.536 & 2 \\
\hline & 0.357 & 0.063 & 0.233 & 0.481 & 219 \\
\hline
\end{tabular}

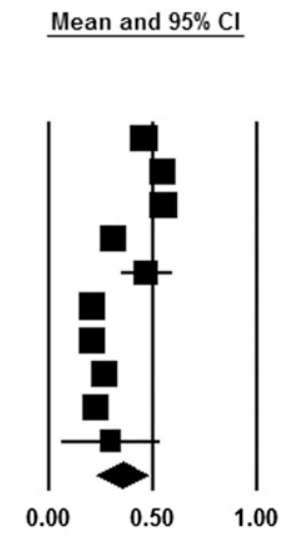

D Study

Statistics

Mean and $95 \% \mathrm{Cl}$

$\begin{array}{lccccc} & \text { Mean } & \begin{array}{c}\text { Standard } \\ \text { error }\end{array} & \begin{array}{c}\text { Lower } \\ \text { limit }\end{array} & \begin{array}{c}\text { Upper } \\ \text { limit }\end{array} & \text { Total } \\ \text { Lindhe et al. (2013) } & 0.710 & 0.006 & 0.698 & 0.722 & 26 \\ \text { Bertl et al. }(2015)^{34} & 0.250 & 0.002 & 0.246 & 0.254 & 185 \\ {\text { Ulm et al. }(2009)^{5}}^{5} & 0.170 & 0.011 & 0.149 & 0.191 & 42 \\ {\text { Ulm et al. }(2009)^{5}}^{5} & 0.370 & 0.017 & 0.336 & 0.404 & 48 \\ & 0.375 & 0.139 & 0.102 & 0.648 & 301\end{array}$

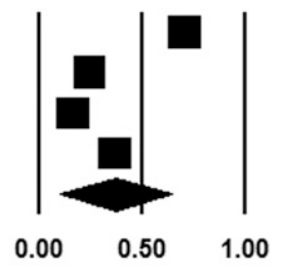

E Study

Bertl et al. (2014)

Bertl et al. (2015) ${ }^{34}$

Bertl et al. (2015) ${ }^{34}$

Fanuscu et al. (2004) ${ }^{36}$

Lindhe et al. (2013)

Moon et al. (2004) ${ }^{42}$

Parsa et al. (2015) ${ }^{43}$

Silthampitag et al. (2011)

Ulm et al. (1997) ${ }^{48}$

Ulm et al. (2009) ${ }^{5}$

Ulm et al. (2009)

Ulm et al. (2009)

Ulm et al. (2009)

Van Dessel $(2013)^{49}$
Statistics

Standard Lower Upper

Mean error limit limit Total

$\begin{array}{lllll}0.200 & 0.013 & 0.175 & 0.225 & 50\end{array}$

$\begin{array}{lllll}0.220 & 0.003 & 0.214 & 0.226 & 185\end{array}$

$\begin{array}{lllll}0.190 & 0.004 & 0.183 & 0.197 & 185\end{array}$

$\begin{array}{lllll}0.150 & 0.021 & 0.108 & 0.192 & 2\end{array}$

$\begin{array}{lllll}0.620 & 0.003 & 0.613 & 0.627 & 33\end{array}$

$\begin{array}{lllll}0.440 & 0.051 & 0.341 & 0.539 & 10\end{array}$

$\begin{array}{lllll}0.370 & 0.051 & 0.269 & 0.471 & 20\end{array}$

$\begin{array}{lllll}0.380 & 0.052 & 0.278 & 0.482 & 3\end{array}$

$\begin{array}{lllll}0.220 & 0.032 & 0.158 & 0.282 & 10\end{array}$

$\begin{array}{lllll}0.310 & 0.013 & 0.285 & 0.335 & 60\end{array}$

$\begin{array}{lllll}0.250 & 0.017 & 0.217 & 0.283 & 23\end{array}$

$\begin{array}{lllll}0.360 & 0.017 & 0.327 & 0.393 & 68\end{array}$

$\begin{array}{lllll}0.250 & 0.013 & 0.224 & 0.276 & 37\end{array}$

$\begin{array}{lllll}0.340 & 0.018 & 0.305 & 0.375 & 8\end{array}$

$\begin{array}{lllll}0.306 & 0.058 & 0.194 & 0.419 & 694\end{array}$

\section{Mean and $95 \% \mathrm{Cl}$}

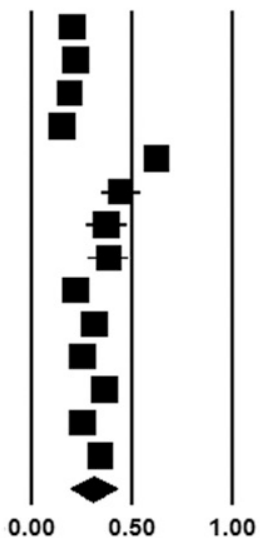

Figure 2.

(Continued)

\section{Heterogeneity and Publication Bias}

The $P$ values of $\chi^{2}$ tests for $Q$ were generally higher than 0.1 , suggesting non-significance of heterogeneity for most meta-analyses, except the studies evaluating atrophic sites $(P=0.06)$ and studies including cadavers $(P=0.02)$. The $P$ was 0 for most meta-analyses, suggesting a non-importance of heterogeneity, except the studies evaluating atrophic sites (56.28\%) and cadaver sites (52.02\%). The two meta-analyses were considered to have moderate to substantial heterogeneity. The $\tau^{2}$ ranged from 0.004 for the meta-analysis evaluating only cadaver samples to 0.08 for the meta-analysis evaluating only samples from the mandibular anterior region. The $\tau^{2}$ values ranged from 0.01 to 0.05 for the rest of the meta-analyses.

The mean TBV of each study was plotted in a funnel plot, with TBV at the horizontal axis and the standard error at the vertical axis for each metaanalysis (see supplementary Fig. 2 in online Journal 


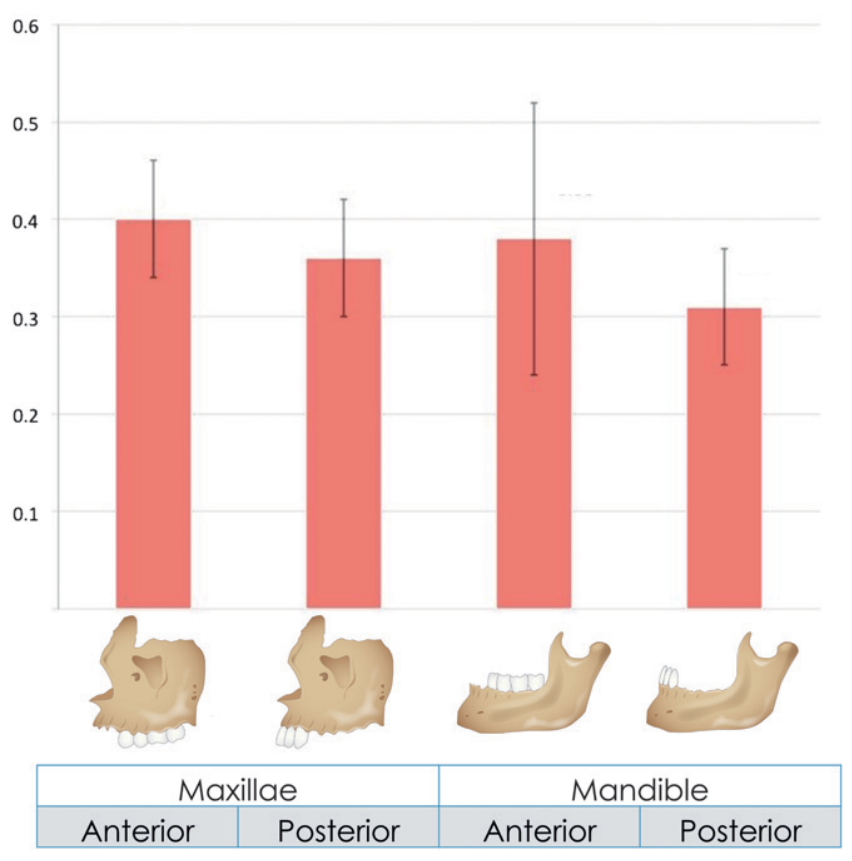

Figure 3.

Mean alveolar bone TBV with 95\% Cl in the different locations of the oral cavity. Note that each illustration represents each edentulous region analyzed.

of Periodontology). The plots showed overall symmetry of the distribution of studies in relation to the WM of TBV, suggesting a low publication bias. Because of the limited study sample size in atrophic, mandibular anterior, and maxillary anterior categories, symmetry could not be assessed.

\section{DISCUSSION}

Alveolar bone density has been regarded as one of the most crucial factors in influencing implant osseointegration in modern implantology. ${ }^{50,51}$ It is a fact that primary or mechanical stability is required to have biologic integration, ${ }^{52}$ particularly in scenarios in which immediate implant loading is to be applied. However, although recent literature ${ }^{53}$ states that even over-drilled implants can achieve osseointegration, its degree still remains unclear. Early studies demonstrated higher implant success rate in the mandible because of its cortical (or compact) bone compared to the maxilla in which the cancellous bone presents with a more porous architecture. ${ }^{18,54}$ Nonetheless, advances in the field along with the incorporation of mechanical engineering/designing (i.e., surface treatment or implant macro-design) have developed a more predictable mechanical stability and, ultimately, osseointegration, regardless of bone quality. ${ }^{55,56}$ As a matter of fact, the term quality has been questioned from the biologic standpoint, claiming that a greater porosity can involve better tissue remodeling with optimum biomechanical integration. ${ }^{22}$ According to this line of thinking, to confuse the higher mineral bone component with an improved bone quality is simplistic. Other parameters might be considered. During bone regeneration, osteocyte lacunar density and area undergo substantial changes. ${ }^{57}$ The number of osteocytes plays a capital role. Osteocytes control resorption of the matrix in which they are embed$\operatorname{ded}^{58}$ and are sensors of biomechanical loading and signal the demand for bone remodeling. ${ }^{59}$ During fracture healing, as in implant insertion, the osteocyte lacunar density is almost twice as high in woven bone compared to mature lamellar bone, exactly as in bone development, during which the density of osteocyte lacunae is higher in woven bone than in lamellar bone. ${ }^{60}$

Conversely, angiogenesis plays a pivotal role in skeletal development and bone fracture repair, and inadequate neoangiogenesis is considered a crucial factor in failed bone formation and remodeling. ${ }^{61}$ It is one of the first events during wound healing and is regulated by a complex growth factor-mediated biochemical signaling system. ${ }^{62}$ In vitro and in vivo studies of osteogenesis and fracture repair have provided a better understanding of the recruitment of vasculature in skeletal development and repair. ${ }^{63}$ The number and distribution of vessels in the nonmineralized bone properties act importantly on bone maturation. ${ }^{64}$ As such, bone non-mineralized fraction and its components might be highlighted in future classification on bone quality.

Hence, it becomes of great importance to apply the adequate loading protocol to avoid its disruption. However, from the clinical point of view, simpler parameters, such as hardness or stiffness of bone, help the clinician in the decision-making processes. For that reason and to provide guidance to clinicians, several classifications based on location or bone quality were proposed. ${ }^{65-67}$ The most popular classification used four scale categories: D4 indicates that poorer bone is found primarily in the posterior maxilla and the denser bone (D1) is often located in the anterior mandible. ${ }^{65}$ It is important to note that these classifications of alveolar bone were based primarily on clinicians' clinical experience and the much higher failure rate obtained from smooth surface implants. ${ }^{68,69}$ Many local (i.e., atrophy or edentulism) or intrinsic (i.e., age or sex) factors have been identified to influence the bone characteristics, ${ }^{47,48,70}$ and results presented have not been able to distinguish the intermediate types of bone. ${ }^{13}$ In fact, Lindhe et al. ${ }^{11}$ showed that in the posterior maxilla, which was described classically as soft bone supplying limited mechanical resistance, such an impression might be only because of a random 

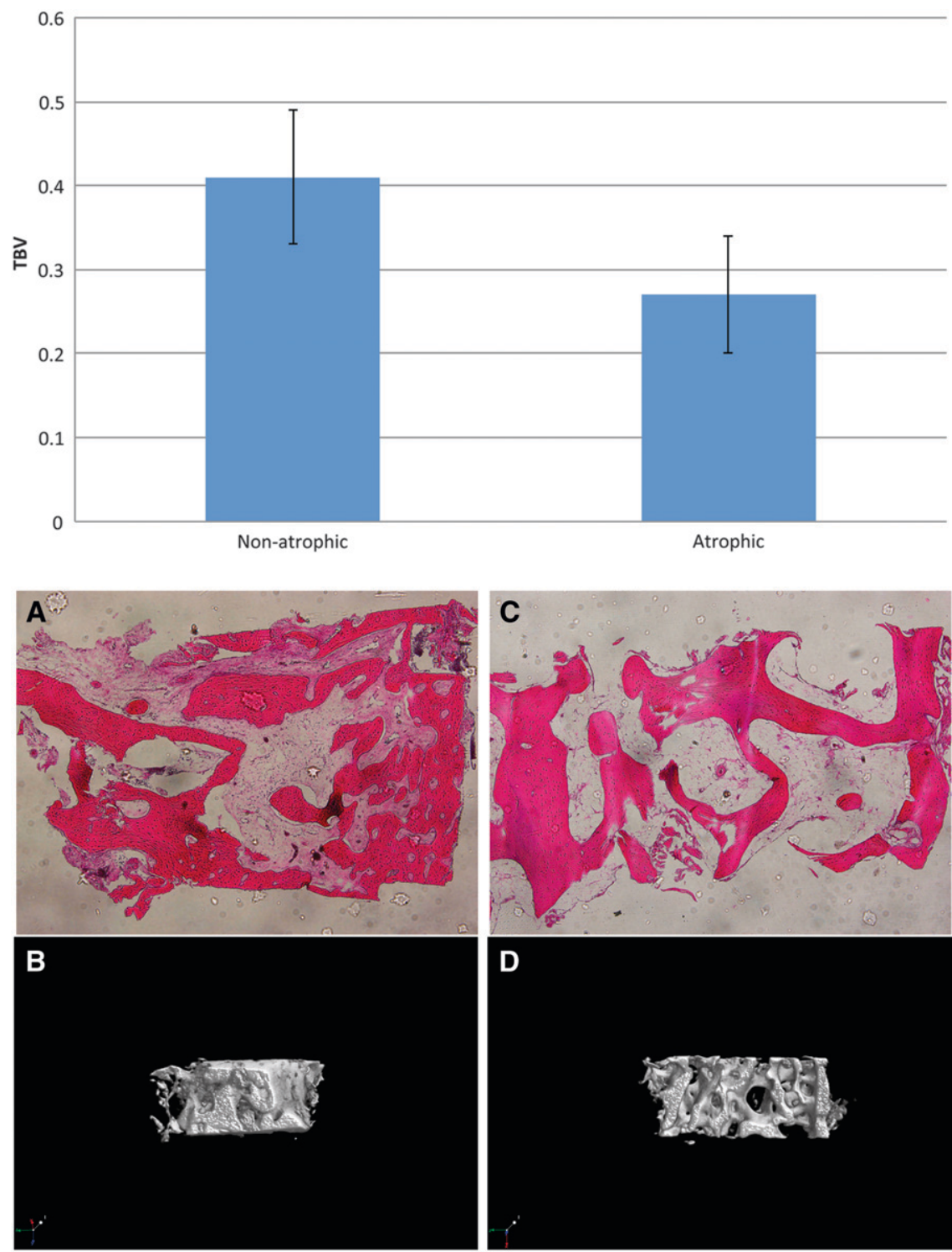

Figure 4.

Alveolar bone TVB (Mean $\pm 95 \%$ Cl) of the atrophic and non-atrophic ridges. A) Hematoxylin and eosin (H\&E) histomorphometric analysis for alveolar bone retrieved from the non-atrophic posterior maxilla. Note that although not very compact bone, Tb.N and Tb.Th indicates denser bone. B) Micro-CT analysis shows the moderate trabecular density. C) H\&E histomorphometric analysis for alveolar bone retrieved from the atrophic posterior maxilla. Note that the large

Tb.Sp displayed indicates lower density. D) Micro-CT analysis shows the low trabecular density. independently, for example, using CBCT to assess alveolar bone architecture. ${ }^{71-73}$ Because of the high heterogeneity among the articles in reporting their results, only a slightly negative correlation could be observed between TBV and Tb.Sp, which is in agreement with some of the previous findings. ${ }^{14,39}$

When the influence of specimen type (cadavers versus living humans) on TBV was analyzed, cadaver studies ${ }^{16,35}$ have generally underestimated the overall TBV when compared to living individuals. Interestingly, to the best of the authors' knowledge, this is the first study to actually report this difference. The observation may be explained by the longer exposure to non-buffered/buffered formalin of the cadaver bone that may eventually alter bone tissue properties. ${ }^{74,75}$ Another reason could be the age of the individuals analyzed. Albeit, the influence of TBV could not be studied because of the wide range, studies investigating alveolar bone in cadavers reported older ages compared to living individuals. Consequently, it could be assumed, although not stated, that bone metabolic diseases (e.g., osteoporosis or arthritis) might exist. Moreover, the likelihood for greater atrophy with age is explained by the "ontologic adaptation" against the mechanical loadings. ${ }^{76}$ As reported previously, sex could be a determinant for bone characteristics (e.g., postmenopausal bone loss). ${ }^{70}$ Again, as a result of the high heterogeneity, this factor could not be studied.

In summary, the results indicate trabecular direction other than the lower density. Hence, this study aims at investigating systematically alveolar bone architecture in the different locations and the factors that could inject bias. Results from this study showed that: 1) although location may lead to discriminating the TBV, it failed to reach statistical significance; and 2) as studied previously, ${ }^{41,47,48}$ the atrophy degree influences negatively TBV. Hence, the data suggest that bone characteristics should not be classified based only on the location but also on examining each case that alveolar bone microarchitecture should not be standardized based only on the location because it has a wide variation in every location.

Several limitations were associated with current study. First, it is important to mention that the samples included did not necessarily follow similar methodology regarding their harvesting or processing. To minimize the risk of bias in this regard, only studies aimed at describing alveolar bone characteristics for implant site evaluation were selected. Hence, the commensurate features were assumed. 


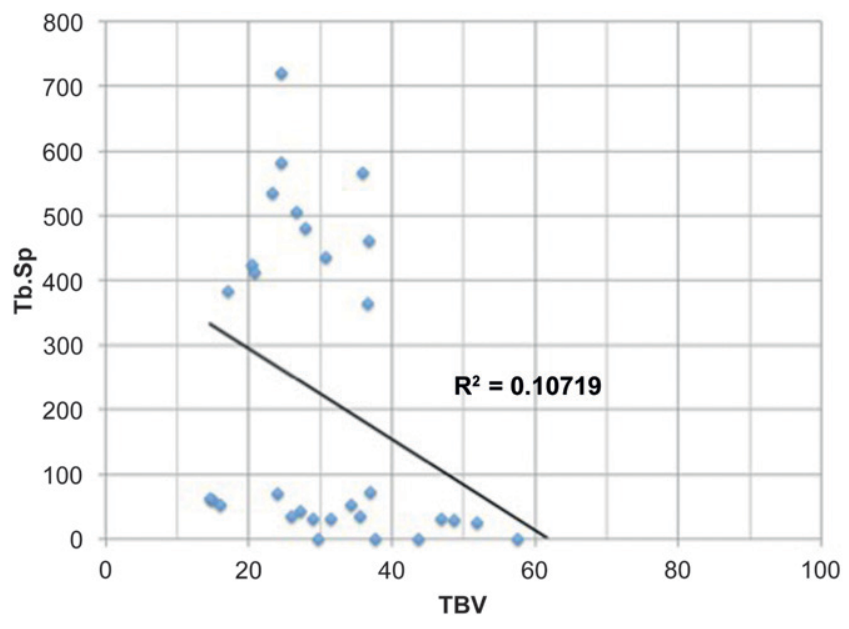

Figure 5.

The correlation between TBV and Tb.Sp. Mean Tb.Sp was plotted against mean TBV of available studies, with $R^{2}=0.1$ I, suggesting a low correlation.

Second, based on the Cochrane Database of Systematic Reviews, only randomized clinical trials should be included for evaluation. ${ }^{77}$ Nonetheless, randomization within these types of intervention cannot be performed because of ethical issues. Hence, the attempt to rank the risk of bias of studies evaluating bone characteristics could not be performed for the NOS. Therefore, a novel scale to score non-randomized case series on bone characteristics for grafted/pristine sites was proposed. High inter-rater agreement was found for appraising all the studies, but it needs additional validation.

\section{CONCLUSIONS}

The present systematic review did not suggest a difference in TBV of alveolar bone among anatomic locations. Likewise, none of the other bone-related parameters studied showed significance. Factors such as status of atrophy and the nature of specimens influence TBV. Hence, implant treatment planning should be based on the actual bone properties and not the anatomic location.

\section{ACKNOWLEDGMENTS}

This study was partially supported by the University of Michigan Periodontal Graduate Student Research Fund and Natural Science Foundation of China Grants 81070813 and 81371190 to FW. The authors report no conflicts of interest related to this study.

\section{REFERENCES}

1. Harada S, Rodan GA. Control of osteoblast function and regulation of bone mass. Nature 2003;423:349-355.
2. Schropp L, Wenzel A, Kostopoulos L, Karring T. Bone healing and soft tissue contour changes following single-tooth extraction: A clinical and radiographic 12-month prospective study. Int $J$ Periodontics Restorative Dent 2003;23:313-323.

3. Pietrokovski J, Massler M. Residual ridge remodeling after tooth extraction in monkeys. J Prosthet Dent 1971; 26:119-129.

4. Pietrokovski J, Massler M. Ridge remodeling after tooth extraction in rats. J Dent Res 1967;46:222-231.

5. Ulm C, Tepper G, Blahout R, Rausch-Fan X, Hienz S, Matejka M. Characteristic features of trabecular bone in edentulous mandibles. Clin Oral Implants Res 2009;20: 594-600.

6. Amler MH, Johnson PL, Salman I. Histological and histochemical investigation of human alveolar socket healing in undisturbed extraction wounds. J Am Dent Assoc 1960;61:32-44.

7. Carlsson GE. Changes in the jaws and facial profile after extractions and prosthetic treatment. Trans $R$ Sch Dent Stockh Umea 1967;12:1-29.

8. Kassolis JD, Reynolds MA. Evaluation of the adjunctive benefits of platelet-rich plasma in subantral sinus augmentation. J Craniofac Surg 2005; 16:280-287.

9. Chan HL, Lin GH, Fu JH, Wang HL. Alterations in bone quality after socket preservation with grafting materials: A systematic review. Int J Oral Maxillofac Implants 2013;28:710-720.

10. Hernandez-Cortes P, Monje A, Galindo-Moreno P, et al. An ex vivo model in human femoral heads for histopathological study and resonance frequency analysis of dental implant primary stability. Biomed Res Int 2014; 2014:535929.

11. Lindhe J, Cecchinato D, Bressan EA, Toia M, Araújo MG, Liljenberg B. The alveolar process of the edentulous maxilla in periodontitis and non-periodontitis subjects. Clin Oral Implants Res 2012;23:5-11.

12. Misch CE. Bone classification, training keys to implant success. Dent Today 1989;8:39-44.

13. Trisi $P$, Rao W. Bone classification: Clinical-histomorphometric comparison. Clin Oral Implants Res 1999;10:1-7.

14. Monje A, González-García R, Monje F, et al. Microarchitectural pattern of pristine maxillary bone. Int $J$ Oral Maxillofac Implants 2015;30:125-132.

15. Blok Y, Gravesteijn FA, van Ruijven LJ, Koolstra JH. Micro-architecture and mineralization of the human alveolar bone obtained with microCT. Arch Oral Biol 2013;58:621-627.

16. Kim YJ, Henkin J. Micro-computed tomography assessment of human alveolar bone: Bone density and three-dimensional micro-architecture. Clin Implant Dent Relat Res 2015;17:307-313.

17. Lindhe J, Bressan E, Cecchinato D, Corrá E, Toia M, Liljenberg B. Bone tissue in different parts of the edentulous maxilla and mandible. Clin Oral Implants Res 2013;24:372-377.

18. Adell R, Lekholm U, Rockler B, Brånemark PI. A 15-year study of osseointegrated implants in the treatment of the edentulous jaw. Int J Oral Surg 1981;10:387-416.

19. Brånemark PI, Hansson BO, Adell R, et al. Osseointegrated implants in the treatment of the edentulous jaw. Experience from a 10-year period. Scand JPlast Reconstr Surg Suppl 1977;16:1-132.

20. Kim Y, Oh TJ, Misch CE, Wang HL. Occlusal considerations in implant therapy: Clinical guidelines with biomechanical rationale. Clin Oral Implants Res 2005; 16:26-35. 
21. Cha JY, Pereira MD, Smith AA, et al. Multiscale analyses of the bone-implant interface. $J$ Dent Res 2015;94:482-490.

22. Davies JE. Understanding peri-implant endosseous healing. J Dent Educ 2003;67:932-949.

23. Davies JE. Mechanisms of endosseous integration. Int J Prosthodont 1998;11:391-401.

24. Parfitt AM. Bone histomorphometry: Proposed system for standardization of nomenclature, symbols, and units. Calcif Tissue Int 1988;42:284-286.

25. Hahn M, Vogel M, Pompesius-Kempa M, Delling G. Trabecular bone pattern factor - A new parameter for simple quantification of bone microarchitecture. Bone 1992;13:327-330.

26. Hildebrand T, Rüegsegger P. Quantification of bone microarchitecture with the structure model index. Comput Methods Biomech Biomed Engin 1997;1:1523.

27. Currey JD. The many adaptations of bone. J Biomech 2003;36:1487-1495.

28. Odgaard A, Gundersen HJ. Quantification of connectivity in cancellous bone, with special emphasis on 3-D reconstructions. Bone 1993;14:173-182.

29. Compston JE. Bone density: BMC, BMD, or corrected BMD? Bone 1995;16:5-7.

30. Shea BJ, Hamel C, Wells GA, et al. AMSTAR is a reliable and valid measurement tool to assess the methodological quality of systematic reviews. J Clin Epidemiol 2009; 62:1013-1020.

31. Moher D, Liberati A, Tetzlaff J, Altman DG; PRISMA Group. Preferred reporting items for systematic reviews and meta-analyses: The PRISMA statement. BMJ2009; 339:b2535.

32. Stang A. Critical evaluation of the Newcastle-Ottawa scale for the assessment of the quality of nonrandomized studies in meta-analyses. Eur J Epidemiol 2010; 25:603-605.

33. Aksoy U, Eratalay K, Tözüm TF. The possible association among bone density values, resonance frequency measurements, tactile sense, and histomorphometric evaluations of dental implant osteotomy sites: A preliminary study. Implant Dent 2009;18:316-325.

34. Bertl K, Subotic M, Heimel P, Schwarze UY, Tangl S, Ulm C. Morphometric characteristics of cortical and trabecular bone in atrophic edentulous mandibles. Clin Oral Implants Res 2015;26:780-787.

35. Bertl K, Heimel P, Reich KM, Schwarze UY, Ulm C. A histomorphometric analysis of the nature of the mandibular canal in the anterior molar region. Clin Oral Investig 2014;18:41-47.

36. Fanuscu MI, Chang TL. Three-dimensional morphometric analysis of human cadaver bone: Microstructural data from maxilla and mandible. Clin Oral Implants Res 2004;15:213-218.

37. Galindo-Moreno P, Moreno-Riestra I, Avila G, et al. Histomorphometric comparison of maxillary pristine bone and composite bone graft biopsies obtained after sinus augmentation. Clin Oral Implants Res 2010;21: 122-128.

38. de Oliveira RC, Leles CR, Lindh C, Ribeiro-Rotta RF. Bone tissue microarchitectural characteristics at dental implant sites. Part 1: Identification of clinical-related parameters. Clin Oral Implants Res 2012;23:981-986.

39. González-García R, Monje F. Is micro-computed tomography reliable to determine the microstructure of the maxillary alveolar bone? Clin Oral Implants Res 2013;24:730-737.
40. Makary C, Rebaudi A, Sammartino G, Naaman N. Implant primary stability determined by resonance frequency analysis: Correlation with insertion torque, histologic bone volume, and torsional stability at 6 weeks. Implant Dent 2012;21:474-480.

41. Monje A, Monje F, González-García R, et al. Influence of atrophic posterior maxilla ridge height on bone density and microarchitecture. Clin Implant Dent Relat Res 2015; 17:111-119.

42. Moon HS, Won YY, Kim KD, et al. The three-dimensional microstructure of the trabecular bone in the mandible. Surg Radiol Anat 2004;26:466-473.

43. Parsa A, Ibrahim N, Hassan $B$, van der Stelt $P$, Wismeijer D. Bone quality evaluation at dental implant site using multislice CT, micro-CT, and cone beam CT. Clin Oral Implants Res 2015;26:e1-e7.

44. Silthampitag P, Klineberg I, Austin B, Jones AS. Bone microarchitecture at oral implant sites in ectodermal dysplasia (ED): A comparison between males and females. Clin Oral Implants Res 2012;23: 1275-1282.

45. Stoppie N, Pattijn V, Van Cleynenbreugel T, Wevers M, Vander Sloten J, Ignace N. Structural and radiological parameters for the characterization of jawbone. Clin Oral Implants Res 2006;17:124-133.

46. Ulm CW, Solar P, Blahout R, Matejka M, Watzek G, Gruber $\mathrm{H}$. Location of the mandibular canal within the atrophic mandible. Br J Oral Maxillofac Surg 1993;31: 370-375.

47. Ulm C, Kneissel M, Schedle A, et al. Characteristic features of trabecular bone in edentulous maxillae. Clin Oral Implants Res 1999;10:459-467.

48. Ulm CW, Kneissel M, Hahn M, Solar P, Matejka M, Donath K. Characteristics of the cancellous bone of edentulous mandibles. Clin Oral Implants Res 1997;8: $125-130$

49. van Dessel N, den Boeft M, van der Wouden JC, et al. Non-pharmacological interventions for somatoform disorders and medically unexplained physical symptoms (MUPS) in adults. Cochrane Database Syst Rev 2014;11:CD011142.

50. Esposito M, Hirsch JM, Lekholm U, Thomsen P. Biological factors contributing to failures of osseointegrated oral implants. (II). Etiopathogenesis. Eur J Oral Sci 1998;106:721-764.

51. Friberg B, Sennerby L, Roos J, Lekholm U. Identification of bone quality in conjunction with insertion of titanium implants. A pilot study in jaw autopsy specimens. Clin Oral Implants Res 1995;6:213-219.

52. Monje A, Suarez F, Garaicoa CA, et al. Effect of location on primary stability and healing of dental implants. Implant Dent 2014;23:69-73.

53. Jimbo R, Tovar N, Yoo DY, Janal MN, Anchieta RB, Coelho PG. The effect of different surgical drilling procedures on full laser-etched microgrooves surfacetreated implants: An experimental study in sheep. Clin Oral Implants Res 2014;25:1072-1077.

54. Henry PJ, Laney WR, Jemt T, et al. Osseointegrated implants for single-tooth replacement: A prospective 5-year multicenter study. Int J Oral Maxillofac Implants 1996;11:450-455.

55. van Velzen FJ, Ofec R, Schulten EA, Ten Bruggenkate CM. 10-year survival rate and the incidence of periimplant disease of 374 titanium dental implants with a SLA surface: A prospective cohort study in 177 fully and partially edentulous patients. Clin Oral Implants Res 2015;26:1121-1128. 
56. Goiato MC, dos Santos DM, Santiago JF Jr., Moreno A, Pellizzer EP. Longevity of dental implants in type IV bone: A systematic review. Int J Oral Maxillofac Surg 2014;43:1108-1116.

57. Kuchler U, Pfingstner G, Busenlechner D, et al. Osteocyte lacunar density and area in newly formed bone of the augmented sinus. Clin Oral Implants Res 2013;24: 285-289.

58. Nakashima T, Hayashi M, Fukunaga T, et al. Evidence for osteocyte regulation of bone homeostasis through RANKL expression. Nat Med 2011;17:1231-1234.

59. Hughes JM, Petit MA. Biological underpinnings of Frost's mechanostat thresholds: The important role of osteocytes. J Musculoskelet Neuronal Interact 2010; 10:128-135.

60. Hernandez CJ, Majeska RJ, Schaffler MB. Osteocyte density in woven bone. Bone 2004;35:1095-1099.

61. Gerstenfeld LC, Cullinane DM, Barnes GL, Graves DT, Einhorn TA. Fracture healing as a post-natal developmental process: Molecular, spatial, and temporal aspects of its regulation. J Cell Biochem 2003;88: 873-884.

62. Einhorn TA. Enhancement of fracture-healing. J Bone Joint Surg Am 1995;77:940-956.

63. Brandi ML, Collin-Osdoby P. Vascular biology and the skeleton. J Bone Miner Res 2006;21:183-192.

64. Galindo-Moreno P, Padial-Molina M, FernándezBarbero JE, Mesa F, Rodríguez-Martínez D, O'Valle F. Optimal microvessel density from composite graft of autogenous maxillary cortical bone and anorganic bovine bone in sinus augmentation: Influence of clinical variables. Clin Oral Implants Res 2010;21:221-227.

65. Misch C. Classifications and treatment options of the completely edentulous arch in implant dentistry. Dent Today 1990;9:26, 28-30.

66. Lekholm U. Surgical considerations and possible shortcomings of host sites. J Prosthet Dent 1998;79:43-48.

67. Truhlar RS, Orenstein IH, Morris HF, Ochi S. Distribution of bone quality in patients receiving endosseous dental implants. J Oral Maxillofac Surg 1997;55(12 Suppl. 5)38-45.

68. Adell R, Eriksson B, Lekholm U, Brånemark PI, Jemt T. Long-term follow-up study of osseointegrated implants in the treatment of totally edentulous jaws. Int J Oral Maxillofac Implants 1990;5:347-359.
69. Jemt T, Lekholm U, Adell R. Osseointegrated implants in the treatment of partially edentulous patients: A preliminary study on 876 consecutively placed fixtures. Int J Oral Maxillofac Implants 1989;4:211-217.

70. Ulm CW, Solar P, Ulm MR, Matejka M. Sex-related changes in the bone mineral content of atrophic mandibles. Calcif Tissue Int 1994;54:203-207.

71. González-García R, Monje F. The reliability of conebeam computed tomography to assess bone density at dental implant recipient sites: A histomorphometric analysis by micro-CT. Clin Oral Implants Res 2013;24: 871-879.

72. Monje A, Monje F, González-García R, Galindo-Moreno $\mathrm{P}$, Rodriguez-Salvanes F, Wang HL. Comparison between microcomputed tomography and cone-beam computed tomography radiologic bone to assess atrophic posterior maxilla density and microarchitecture. Clin Oral Implants Res 2014;25:723-728.

73. Benavides E, Rios HF, Ganz SD, et al. Use of cone beam computed tomography in implant dentistry: The International Congress of Oral Implantologists consensus report. Implant Dent 2012;21:78-86.

74. Fonseca AA, Cherubini K, Veeck EB, Ladeira RS, Carapeto LP. Effect of $10 \%$ formalin on radiographic optical density of bone specimens. Dentomaxillofac Radiol 2008;37:137-141.

75. Currey JD, Brear K, Zioupos P, Reilly GC. Effect of formaldehyde fixation on some mechanical properties of bovine bone. Biomaterials 1995;16:1267-1271.

76. Frost HM. Wolff's Law and bone's structural adaptations to mechanical usage: An overview for clinicians. Angle Orthod 1994;64:175-188.

77. Lefebvre C, Glanville J, Wieland LS, Coles B, Weightman AL. Methodological developments in searching for studies for systematic reviews: Past, present and future? Syst Rev 2013;2:78.

Correspondence: Dr. Alberto Monje, Department of Periodontics and Oral Medicine, University of Michigan School of Dentistry, 1011 N. University Ave., Ann Arbor, MI 48109-1078. Fax: 734/936-0374; e-mail: amonjec@ umich.edu.

Submitted April 21, 2015; accepted for publication June 19, 2015. 